Article

\title{
Does Religious Involvement Generate or Inhibit Fear of Crime?
}

\section{Todd Matthews ${ }^{1}{ }^{*}$, Lee Michael Johnson ${ }^{2}$ and Catherine Jenks ${ }^{2}$}

1 Department of Sociology, University of West Georgia, 1601 Maple Street, Carrollton, GA 30118, USA

2 Department of Criminology, University of West Georgia, 1601 Maple Street, Carrollton, GA 30118, USA; E-Mails: ljohnson@westga.edu (L.M.J.); cjenks@westga.edu (C.J.)

* Author to whom correspondence should be addressed; E-Mail: tmatthew@westga.edu; Tel.: +1-678-839-6305; Fax: +1-678-839-6506.

Received: 15 June 2011; in revised form: 11 September 2011 / Accepted: 23 September 2011 / Published: 27 September 2011

\begin{abstract}
In victimology, fear of crime is understood as an emotional response to the perceived threat of crime. Fear of crime has been found to be affected by several variables besides local crime rates and personal experiences with victimization. This study examines the relationship between religion and fear of crime, an underexplored topic in the criminological literature. This gap is rather surprising given the central role religion has been found to play in shaping the attitudes and perceptions of congregants. In particular, religion has been found to foster generalized trust, which should engender lower levels of distrust or misanthropy, including that which is directed towards a general fear of crime. OLS regression was performed using data from the West Georgia Area Survey $(n=380)$. Controlling for demographic, community involvement, and political ideology variables, frequency of religious attendance was significantly and negatively associated with fear of property crime. This relationship remained even after a perceived neighborhood safety variable was introduced to the model. However, religious attendance was not significantly related to fear of violent crime, and religious orientation was unrelated to fear of property and violent crime. These results suggest that religious involvement conditionally reduces fear of crime, and the authors recommend that future research explore relationships between religion and fear of crime.
\end{abstract}

Keywords: fear of crime; religious orientation; religious attendance; survey 


\section{Abbreviations}

WGAS: West Georgia Area Survey; OLS: Ordinary Least Squares; US: United States

\section{Introduction/Background}

The body of literature on religion and crime pays a great deal of attention to the role of religion in crime etiology and criminal justice practice [1]. In a recent article, Akers reviewed multiple studies showing negative relationships between religion and crime, noting that religious extremism, however, may be associated with increased crime [1]. Baier and Wright's meta-analysis of 60 studies showed that religious beliefs and behaviors moderately deterred criminal behavior [2]. However, victimological analyses of religion are largely missing from this literature. This oversight is surprising given the central role religion has been found to play in shaping the attitudes and perceptions of its adherents. The purpose of the current study, therefore, is to test whether religious involvement reduces fear of crime.

\subsection{Fear of Crime and Religion}

Ferraro and LaGrange defined fear of crime as "an emotional response of dread or anxiety to crime or symbols that a person associates with crime" [3]. More specifically, individuals fear the harm or loss resulting from criminal acts, and not simply the existence of actions labeled as "crimes" [4]. This fear is produced by one's perceived risk of crime, which is "a recognition of a situation as possessing at least potential danger, real or imagined" [3]. It is important to distinguish between these concepts: fear of crime refers to an emotive state of being afraid of being victimized by crime while perceived risk of crime refers to a cognitive assessment of one's chances of being victimized. As measured variables, perceived high risk of crime should increase levels of fear of crime, although the two are not necessarily highly correlated. Some people, for example, may perceive high risk of crime but not be highly afraid of it [5]. Further, these concepts should not be confused with general concern over crime [5], which has more to do with recognition of crime as a social problem. General concern does not necessarily equate with fear and perceived risk. For example, a person can believe that a community or society has a significant crime problem without thinking that $\mathrm{s} / \mathrm{he}$ has a significant chance of being personally victimized or being very afraid of crime.

Past research suggests that fear of both violent crime and property crime is widespread across the public and is a social problem separate from crime itself, although most people are not likely highly fearful of crime on a daily basis [6]. Zhao, Lawton, and Longmire [7] found that living in close proximity to crime events increased residents' fear of crime. Other research shows a lack of correspondence between fear of crime and official crime rates, with fear appearing to over- or underestimate actual crime threats [8]. Regardless, it is apparent from research on fear of crime that such fear is not simply a reaction to area crime rates and personal experiences with victimization.

A number of studies suggest that fear of crime is also the result of several personal as well as ecological and community level factors [5,9]. While personal and demographic variables such as age, gender, income, education, race, health, and victimization are frequently studied, religious orientation or behavior variables are rarely included in models examining fear of crime. Previous research showed 
that religiosity is an important factor of public perceptions of criminal behavior in that the strength of religious belief is positively related to punitive and morally indignant responses to crime [10]. It appears that more religious persons may have more "tough on crime" attitudes, but how fearful do they tend to be of crime? This oversight in the literature is curious, given that religious affiliation ties persons to social networks offering resources that can be used to respond to threats to well-being such as crime. Additionally, and perhaps most crucially, religious affiliation has been found to build generalized trust (trust in others unknown to us) in participants [11-18]. This form of trust has been characterized as "the foundation of a civil society... (that) eases the way toward getting people to work together" [19]. Religious participation or affiliation is seen as a central pathway for the generation of such trust, a contention extending back in American social thought to Alexis de Tocqueville's Democracy in America almost two centuries ago. Contemporary scholars maintain that religious institutions play a vital role in the development of generalized trust today [16-18].

This trust in others beyond our immediate social milieu is critical in our complex, specialized world, reducing social risk and fears and enabling day-to-day social action to continue relatively unimpeded [20,21]. Excessive fear of external actors and social conditions, both known and unknown, would paralyze the modern social world, as individuals would be too fearful or mistrusting to engage in any sort of "risky" action. Thus, elevated levels of generalized trust should engender lower levels of distrust or misanthropy, including that which is directed towards a general fear of crime. Excessive fear of crime can cause such social paralysis, as it leads to significant changes in individual and collective behavior and can truly alter social relations. Despite the apparent link between religion, trust, and perceptions of crime, only a few studies examining the relationship between religion and fear of crime could be found.

Lotz tested for the relative impacts of experienced victimization versus indicators of resistance to social change that included religion and political conservatism [22]. In a sample of residents in Washington state in the US, Lotz found that religion and political conservatism were slightly associated with increased concern over but not fear of crime while victimization was slightly associated with increased fear of but not concern over crime. The results suggest that fear results from practical crime threats but concern results from socio-political ideology [22].

O'Mahony and Quinn tested if community-related factors explain fear of crime better than individual factors, including one's religious participation [23]. Prior research using national samples suggest that Protestants are more worried about terrorist attacks than Catholics in Northern Ireland. Using community-based survey data, however, O'Mahony and Quinn found in a multivariate model that community type and respondent satisfaction with the community significantly determined fear of crime while individual characteristics, including one's religion, did not [23]. It is important to recognize here that the community type measure they used is partly defined by religious composition (groupings included "Catholic Lower Working Class Urban," "Protestant Small Towns," etc.) [23]. Thus, while their study suggests that individuals' religious affiliation alone does not determine their fear of crime, it does not suggest that religion plays no part in determining fear of crime.

Sacco and Nakhaie included religiosity among several demographic variables in their analysis of age and crime-coping adaptations in a Canadian national sample [24]. The researchers argue for and used behavioral, rather than perceptual, outcome measures of fear of crime. These behaviors included "carrying something for self-defense, locking car doors when alone, checking the back seat of the car 
for intruders, planning their route with safety in mind, and staying at home at night because they are afraid" [24]. Results showed that among nonelderly respondents only, the religious (compared to the non-religious) were more likely to engage in some of the behaviors-lock car doors, plan a safe route, and stay home for fear. However, Sacco and Nakhaie's behavioral measures of fear of crime are controversial as they may actually indicate a separate subjective reaction to a crime construct, behavioral reactions to crime, and not fear of crime that is widely understood as an emotional state [24].

Mohammed, Saridakis, and Sookram included a dichotomous measure of religion (religious affiliation/no religious affiliation) as a control variable in their analysis of the impact of victimization upon fear of crime - also a dichotomous measure (fearful/not fearful of crime) in a national sample from Trinidad and Tobago [25]. The researchers report that persons with a religious affiliation were more likely to be fearful of crime than those without a religious affiliation, a result they found to be counter-intuitive.

Clearly, more studies are needed if the relationship between religion and fear of crime is to be understood. Aside from being too few, religion was not the focus of prior studies and they used dated or questionable measures of fear of crime, such as those noted in the review above.

\subsection{The Current Study}

The current study tests for a possible association between religious involvement and fear of crime. Frequency of attendance at religious services and religious orientation will serve as the primary independent variables of interest in models examining fear of crime as an outcome. Because of the paucity and inconsistency of past research on religion and fear of crime, a positive or negative relationship between the two will not be hypothesized. Generalized trust is included to see if it has effects independent of religious attendance and religious orientation. Also, an index of civic engagement is included here, as those who participate more broadly in social life should also generally be more trusting and less fearful. Further, political orientation, community tenure, and civic participation are added as potentially competing independent variables. If religious involvement is associated with fear of crime, it will be important to explore the possibility that liberal $v s$. conservative identity or community ties in general, not religious activity specifically, are actually affecting people's fear of crime. As O'Mahony and Quinn point out, it may be the lived experiences within the community that determines fear of crime more than religion and other personal factors [23]. Finally, prior victimization is included as a potential independent variable, even though past research does not indicate that objective experience with crime is a strong predictor of fear of crime [5].

The models also contain a set of demographic control variables: age, gender, race, and education. Past research shows that fear of crime varies according to personal factors [5]. Two key factors here are age and gender. Earlier studies suggested that older persons have higher fear but more rigorous recent research has revealed complex relationships. For example, Ferraro found a curvilinear relationship with age: the young, not elders, had the highest levels of fear while middle-aged adults had the lowest [5]. Concerning gender, studies consistently show that women have higher levels of fear of crime, including crimes in which women are not more likely to be victimized [5]. It is possible that fear of sexual assault elevates women's fear of other crimes. Because women are at higher risk of sexual assault, it may operate as a master offense that increases their fear of other crimes, especially 
those with the potential to lead to sexual victimization [26]. Research by Ferraro [26] and Fisher and Sloan [27] supported hypotheses that women's fear of general crime shadows their fear of sexual assault. However, this research focused little on how risk shapes men's fear of crime. Reid and Conrad [28] found that women reported higher levels of fear of sexual assault but also that perceived risk had a greater cumulative impact on men's fear of robbery, a crime in which men are more likely to be victimized. The shadow effect in women's fear of crime appears to be part of a larger gender differences picture. As Schafer, Huebner, and Bynum's [29] research shows, men and women's experiences in fearing victimization are likely determined by different factors. Also, gender differences may lie in the reporting itself. To protect masculine self-identity, men may under-report their levels of fear. Sutton and Farrall [30] found evidence that men's, but not women's, reports of fear of crime is influenced by social desirability. At any rate, in this analysis of the impact of religious participation on fear of crime, it is important to consider the impact of gender.

Finally, fear of crime could be an outcome of the extent to which one finds the neighborhood to be a safe place. Assessments of the presence of danger in the community, where people spend a great deal of time, are likely to influence fear of crime. Several studies find that neighborhood characteristics and perceptions of one's neighborhood affect fear of crime [see for example 7,9,31-33]. Further, like community tenure and civic participation, feeling safe in the neighborhood could be an indicator of community attachment - a "safe place" could be part of a favorable definition of a community. Thus, a measure of how safe one feels in the neighborhood will also be included. A total of four models will be tested: two examining fear of violent crime and two examining fear of property crime.

\section{Results and Discussion}

\subsection{Data}

In Fall 2010, the Survey Research Center at the University of West Georgia launched the West Georgia Area Survey (WGAS). The 2010 WGAS was a first of its kind social scientific phone survey of the seven county core of the West Georgia region, an area of roughly 650,000 people on the western fringe of the larger Atlanta metropolitan area. These counties were selected due to their geographical proximity and general demographic similarities with Carroll County, GA, which is the home county of the University of West Georgia. The WGAS was designed to follow from decades-long studies like the General Social Survey (National Opinion Research Center at the University of Chicago), the Houston Area Survey (Rice University), the Baton Rouge Area Survey (Louisiana State University), the Mississippi Poll (Mississippi State University) and other similar social science attempts to empirically assess attitudes and behaviors regarding topical issues of the day. Another study of particular influence was political scientist Robert Putnam's Social Capital Benchmark Survey. This study was conducted with a nationally representative sample and with dozens of communities across the United States. Topics and questions were drawn from these previous studies as appropriate to fit the purposes of the WGAS principal investigators.

A landline random digit dialing sample was generated for the Survey Research Center by Survey Sampling Incorporated, and the survey was administered using Computer Assisted Telephone Interview software over a six week period from late October to early December. The sample was first 
drawn proportionally from each of the seven counties, based on the most recent Census population estimates. Households were then randomly drawn from within each county. The most recent birthday was used as the final step in sampling individuals within the households contacted.

The survey contained questions on a wide range of topics, including: demographics and contextual variables; community life and social trust; civic involvement; environmental concern and water issues; and fear of crime and victimization. The average completion time for respondents was approximately 20 minutes. The final number of completed surveys was 380 , with a response rate of $22 \%$. While the response rate was lower than ideal (though not excessively so today), non-response bias was counteracted by generating a true random digit dialing sample, utilizing refusal conversion, and matching our demographics to local Census estimates, weighting those that were significantly different (such as age). The final dataset was roughly representative of major demographic characteristics in the study region except for the age of respondents. This is a fairly consistent reality today for those who engage in landline-based telephone surveys, as older respondents tend to be more likely to both have a landline and to use it as compared to younger respondents. Thus the decision was made to weight the data based on the age of the survey respondent. It should be noted that the models were run by the researchers both with and without weighting, with no major differences emerging.

\subsection{Measures}

The dependent variables utilized in the regression models include an index of fear of property crime and an index of fear of violent crime. Ferraro points out that sound measures of fear of crime should (1) tap into the emotion of fear or worry, not judgments or concerns, (2) refer to the type of victimization, not "crime" generically, (3) take aim at the subject's everyday life, not hypothetical situations or ones subjects may intentionally avoid, and (4) avoid double-barreled items, asking what subjects hypothetically or actually do for example [5]. Also, to best measure fear of crime in survey research, multi-item measures are essential [5]. The current analysis uses the fear of crime measure developed by Ferraro and Lagrange to respond to these criteria [5].

Two indices were constructed from a series of ten statements where respondents were asked to rate their fear of each on a scale of 1-10, where 1 indicated no fear at all, and 10 meant that the respondent was very afraid. The indicators of fear of property crime included:

- being approached on the street by a beggar or panhandler

- being cheated, conned, or swindled out of your money

- having someone break into your home while you are away

- having your car stolen

- having your property damaged by vandals

The indicators of fear of violent crime included:

- having someone break into your home while you are there

- being raped or sexually assaulted

- being murdered

- being attacked by someone with a weapon

- being robbed or mugged on the street 
The possible values for each index range from 5-50. The mean score for the property crime index was 22.02, and the mean score for the violent crime index was 23.19. Both indices exhibit a high degree of reliability: for the property crime index, the Cronbach's alpha was 0.831 , while the Cronbach's alpha for the violent crime index was 0.935 .

The demographic variables in the regression models include race (dichotomized to white and black/other); education, a six-point ordinal variable ranging from less than high school to graduate or professional degree; gender; political ideology, which includes conservative, moderate, liberal and those who "haven't thought about it"; years lived in community, a six-point ordinal variable ranging from "less than one year" to "all your life"; a civic participation index, measuring participation in a wide range of community life, ranging from 0-15 types of activities; and generalized trust, recoded into two dummy variables ("people can be trusted" and "depends," with "you cannot be too careful" as the reference group). Descriptive statistics for all the variables used in the regression models, are found in Table 1.

The focal independent variables of interest include two measures of religious life often used by researchers, frequency of religious attendance and religious orientation. The frequency of religious attendance variable asked "(n)ot including weddings and funerals, how often do you attend religious services?" Options ranged from every week to less often than once a year. Just fewer than forty percent of respondents reported attending religious services every week, while each of the other categories fell in the ten to twenty percent range. The variable was reverse coded for the regression analyses. The orientation question captured broad religious preferences, including Protestantism, Catholicism, another type of Christianity, Judaism, some other religion, or no religion. Protestantism was the most frequently cited preference, with $64.1 \%$ choosing this option. Other Christians were $15.5 \%$ of the respondents, while those with no religion were $9.3 \%$, Catholics made up $7.5 \%$, and those representing other religions were $3.6 \%$ of total respondents in the survey.

The other focal variables of interest for the researchers were previous victimization (either of a property crime or a violent crime respectively), and the respondent's feeling of safety at night in one's neighborhood. Over $42 \%$ of respondents reported having been a victim of property crime at some point in their lives, while $18.9 \%$ reported having been a violent crime victim. Feeling of safety at night in one's neighborhood is a measure that was used in earlier research to measure fear of crime, though Ferraro and Lagrange contend that it is likely a better indicator of perceived risk than fear [5].

While feeling of safety at night in one's neighborhood is moderately correlated with both the fear of property crime index and the fear of violent crime index, VIF diagnostics run for each regression model indicate no problems with multicollinearity. Slightly less than half of the respondents (45.2\%) reported that they felt very safe in their neighborhood at night, while $41.2 \%$ felt somewhat safe, and only $13.6 \%$ reported feeling somewhat or very unsafe.

Ordinary Least Squares (OLS) regression analysis is used to examine whether the frequency of religious attendance and/or the respondent's religious orientation are predictors of fear of property crime and fear of violent crime, net of the effects of the respondent's general feeling of nighttime safety in their neighborhood and of the demographic variables. As noted above, Table 1 presents the descriptive statistics for all variables included in the analysis. Table 2 includes two models displaying the results of the OLS regression of the predictor variables on fear of property crime. In Table 3, there are two models presented which show the results of OLS regression of the predictor variables on fear 
of violent crime. In both Table 2 and Table 3, the first model includes the demographic variables, the previous victimization measure and the respondent's feeling of safety. The second model in both tables incorporates the measures from the first model, while adding in religious attendance and religious denomination.

Table 1. Descriptive Statistics.

\begin{tabular}{|c|c|c|}
\hline Variables & Percent or Mean & Nor SD \\
\hline Property Crime index $($ Range $=5-50)$ & 22.4 & 11.3 \\
\hline Violent Crime index (Range $=5-50)$ & 24.8 & 15.1 \\
\hline \multicolumn{3}{|l|}{ Religious attendance } \\
\hline Every week & 38.5 & 136 \\
\hline Almost every week & 11.9 & 42 \\
\hline Once or twice a month & 15.0 & 53 \\
\hline A few times each year & 18.7 & 66 \\
\hline Less often than that & 15.9 & 56 \\
\hline \multicolumn{3}{|l|}{ Religious denomination } \\
\hline Protestant & 64.1 & 232 \\
\hline Catholic & 7.5 & 27 \\
\hline Other Christian & 15.5 & 56 \\
\hline Other Religion & 3.6 & 13 \\
\hline No Religion & 9.3 & 34 \\
\hline Race (1=Black or Other $)$ & 17.5 & 65 \\
\hline \multicolumn{3}{|l|}{ Education } \\
\hline Less than high school & 2.0 & 7 \\
\hline Some high school & 3.1 & 11 \\
\hline Graduated high school/GED & 19.1 & 71 \\
\hline Some college/AA/Vocational or trade school & 43.2 & 161 \\
\hline College graduate & 17.5 & 65 \\
\hline Graduate or professional degree & 15.1 & 56 \\
\hline Gender $(1=$ Male $)$ & 31.1 & 116 \\
\hline \multicolumn{3}{|l|}{ Political ideology } \\
\hline Conservative & 53.1 & 197 \\
\hline Moderate & 19.9 & 75 \\
\hline Liberal & 13.5 & 51 \\
\hline Haven't thought about it & 13.5 & 51 \\
\hline \multicolumn{3}{|l|}{ Years lived in community } \\
\hline Less than one year & 4.3 & 16 \\
\hline One to five years & 26.4 & 99 \\
\hline Six to ten years & 20.8 & 78 \\
\hline Eleven to twenty years & 16.3 & 61 \\
\hline More than twenty years & 23.1 & 86 \\
\hline All your life & 9.1 & 34 \\
\hline Civic participation index $($ Range $=0-15)$ & 3.2 & 2.6 \\
\hline \multicolumn{3}{|l|}{ Generalized trust } \\
\hline People can be trusted & 36.6 & 136 \\
\hline Depends & 5.7 & 21 \\
\hline You can't be too careful & 57.7 & 215 \\
\hline Victim of Property Crime $(1=$ Yes $)$ & 42.5 & 159 \\
\hline Victim of Violent Crime $(1=$ Yes $)$ & 18.9 & 71 \\
\hline \multicolumn{3}{|l|}{ Feeling of safety during night in neighborhood } \\
\hline Very safe & 45.2 & 168 \\
\hline Somewhat safe & 41.2 & 153 \\
\hline Somewhat or very unsafe & 13.6 & 50 \\
\hline
\end{tabular}




\subsection{Analysis}

Table 2 includes the results of the OLS regression models of the predictors of fear of property crime. Model 1 focuses on the demographic variables, previous property crime victimization, and the respondent's feeling of safety. Several demographic variables emerge as significant predictors of fear of property crime in this model. Gender $(\beta=-0.122, \mathrm{p}<0.05)$ displays a significant and negative relationship with fear of property crime, indicating that male respondents are much less fearful of property crime than female respondents, controlling for all other variables in the model. Also significant and negative is one of the comparison groups for political ideology, those who "haven't thought about" where they stand ideologically $(\beta=-0.130, \mathrm{p}<0.05)$. Respondents in this category are much less afraid of property crime than the reference group of ideological conservatives. Years lived in community is also significant and negative $(\beta=-0.123, \mathrm{p}<0.05)$, thus those respondents who lived in their community longer showed less fear of property crime than those who had been there a shorter time. Also, those who exhibit higher levels of trust were significantly less fearful of property crime than those who believe you cannot be too careful with others $(\beta=-0.212, p<0.001)$. Being the victim of a property crime was not statistically significant. However, the respondent's feeling of safety during the night in the neighborhood was highly significant and negative for both groups versus the reference group. Those who felt very safe $(\beta=-0.457, \mathrm{p}<0.001)$ and those who felt somewhat safe $(\beta=-0.225$, $\mathrm{p}<0.01)$ expressed lower levels of fear of property crime compared to those who felt somewhat unsafe or unsafe in their neighborhood at night.

Model 2 of Table 2 adds the respondent's religious participation and religious attendance to the predictors utilized in Model 1. Regarding the religious participation variables, religious attendance is significant and negative $(\beta=-0.137, \mathrm{p}<0.05)$. Those who attend religious services more frequently exhibit less fear of property crime than those who attend less frequently, net of the other variables in the model. Further, Protestants $(\beta=0.239, \mathrm{p}<0.05)$ and Catholics $(\beta=0.162, \mathrm{p}<0.05)$ each reported significantly higher levels of fear of property crime when compared to the reference group of the nonreligious. However, the inclusion of this variable did not reduce to insignificance the variables that were significant in the previous model. Gender $(\beta=-0.138, \mathrm{p}<0.01)$ was again significant and negative, with male respondents displaying less fear of property crime than female respondents ${ }^{1}$. Those who "haven't thought about" where they stand ideologically were again less fearful of property crime than conservatives $(\beta=-0.147, \mathrm{p}<0.05)$. Years lived in community was again significant and negative as well $(\beta=-0.126, p<0.05)$. Those who exhibit higher levels of trust were again significantly less fearful of property crime than those who believe you cannot be too careful with others $(\beta=-0.210, \mathrm{p}<0.001)$. Finally, the respondent's feeling of safety during the night in the neighborhood was highly significant and negative for both groups versus the reference group. Those who felt very safe $(\beta=-0.472, p<0.001)$ and those who felt somewhat safe $(\beta=-0.243, p<0.01)$ again expressed lower levels of fear of property crime compared to those who felt somewhat unsafe or unsafe in their neighborhood at night.

1 In response to reviewer comments, we also performed an analysis of violent crime where rape/sexual assault was excluded, as it was argued that the difference in fear between men and women may be due to the inclusion of this single item. We found that women in our sample were still more fearful of violent crime when rape/sexual assault was excluded from the index. 
Table 2. Ordinary Least Squares (OLS) Regression of Predictors of Fear of Property Crime.

\begin{tabular}{|c|c|c|c|c|c|c|c|c|}
\hline & \multicolumn{4}{|c|}{ Model 1} & \multicolumn{4}{|c|}{ Model 2} \\
\hline & b & Sig & SE & $\beta$ & b & Sig & SE & $\boldsymbol{\beta}$ \\
\hline \multicolumn{9}{|l|}{ Race (White reference) } \\
\hline Black or other & -0.650 & & 1.485 & -0.022 & -0.777 & & 1.568 & -0.027 \\
\hline Education & -0.263 & & 0.534 & -0.026 & -0.174 & & 0.557 & -0.017 \\
\hline \multicolumn{9}{|l|}{ Gender (Female reference) } \\
\hline Male & -2.956 & $*$ & 1.210 & -0.122 & -3.397 & $* *$ & 1.301 & -0.138 \\
\hline \multicolumn{9}{|l|}{$\begin{array}{l}\text { Political ideology (Conservative } \\
\text { reference) }\end{array}$} \\
\hline Moderate & 0.948 & & 1.426 & 0.034 & -0.373 & & 1.556 & -0.013 \\
\hline Liberal & -2.656 & & 1.662 & -0.083 & -3.252 & & 2.016 & -0.090 \\
\hline Haven't thought about it & -4.400 & $*$ & 1.783 & -0.130 & -5.110 & $*$ & 1.961 & -0.147 \\
\hline Years lived in community & -0.962 & $*$ & 0.398 & -0.123 & -0.981 & $*$ & 0.423 & -0.126 \\
\hline Civic participation index & 0.267 & & 0.223 & 0.061 & 0.312 & & 0.246 & 0.070 \\
\hline \multicolumn{9}{|l|}{$\begin{array}{l}\text { Generalized trust (You can't be } \\
\text { too careful reference) }\end{array}$} \\
\hline People can be trusted & -4.933 & $* * *$ & 1.180 & -0.212 & -4.936 & $* * *$ & 1.237 & -0.210 \\
\hline Depends & -3.414 & & 2.346 & -0.073 & -2.157 & & 2.536 & -0.044 \\
\hline Ever Victim of Property Crime & -0.776 & & 1.161 & -0.034 & -0.755 & & 1.240 & -0.033 \\
\hline \multicolumn{9}{|l|}{$\begin{array}{l}\text { Feeling of safety at night in } \\
\text { neighborhood (Somewhat or } \\
\text { very unsafe reference) }\end{array}$} \\
\hline Very safe & -10.227 & $* * *$ & 1.717 & -0.457 & -10.717 & $* * *$ & 1.862 & -0.472 \\
\hline Somewhat safe & -5.084 & $* *$ & 1.683 & -0.225 & -5.563 & $* *$ & 1.876 & -0.243 \\
\hline Religious attendance & & & & & -1.019 & $*$ & 0.464 & -0.137 \\
\hline \multicolumn{9}{|l|}{$\begin{array}{l}\text { Religious denomination (Non- } \\
\text { religious reference) }\end{array}$} \\
\hline Protestant & & & & & 5.780 & $*$ & 2.822 & 0.239 \\
\hline Catholic & & & & & 6.712 & $*$ & 3.317 & 0.162 \\
\hline Other Christian & & & & & 3.569 & & 3.090 & 0.114 \\
\hline Other Religion & & & & & 6.501 & & 4.273 & 0.104 \\
\hline Constant & 37.062 & $* * *$ & 3.149 & & 35.933 & $* * *$ & 4.125 & \\
\hline R-Squared & 0.224 & & & & 0.247 & & & \\
\hline
\end{tabular}

$*$ Sig at $\mathrm{p}<0.05 ; * *$ Sig at $\mathrm{p}<0.01 ; * * *$ Sig at $\mathrm{p}<0.001$

The results of the OLS regression models of the predictors of fear of violent crime are found in Table 3. Again, Model 1 focuses on the demographic variables, previous property crime victimization, and the respondent's feeling of safety. Only gender, generalized trust, and feeling of safety at night in the neighborhood emerged as significant predictors of fear of violent crime. Gender $(\beta=-0.278$, $\mathrm{p}<0.001$ ) has a highly significant and negative relationship with fear of violent crime, displaying an even more powerful effect than it did on fear of property crime. Male respondents are much less fearful of violent crime than female respondents, controlling for all other variables in the model. Those who exhibit higher levels of trust were significantly less fearful of violent crime than those who believe you cannot be too careful with others $(\beta=-0.184, \mathrm{p}<0.001)$, while those who said that it depends were also less fearful of violent crime than the reference group $(\beta=-0.100, p<0.05)$. Finally, 
the respondent's feeling of safety during the night in the neighborhood was highly significant and negative for those who felt very safe $(\beta=-0.369, \mathrm{p}<0.001)$ versus the reference group.

Model 2 of Table 3 incorporates the religious participation variables along with the predictors of fear of violent crime utilized in Model 1. Neither religious attendance nor any of the denomination variables are statistically significant. Gender remained highly significant and negative $(\beta=-0.272$, $\mathrm{p}<0.001$ ), with male respondents once again displaying less fear of violent crime than female respondents. Those who reported higher levels of trust were again significantly less fearful of violent crime $(\beta=-0.176, \mathrm{p}<0.01)$, and the respondent's feeling of safety during the night in the neighborhood was highly significant and negative for those who felt very safe $(\beta=-0.378, p<0.001)$ versus the reference group.

Table 3. OLS Regression of Predictors of Fear of Violent Crime.

\begin{tabular}{|c|c|c|c|c|c|c|c|c|}
\hline & \multicolumn{4}{|c|}{ Model 1} & \multicolumn{4}{|c|}{ Model 2} \\
\hline & $\mathbf{b}$ & Sig & $\mathbf{S E}$ & $\boldsymbol{\beta}$ & $\mathbf{b}$ & Sig & $\mathbf{S E}$ & $\boldsymbol{\beta}$ \\
\hline \multicolumn{9}{|l|}{ Race (White reference) } \\
\hline Black or other & -2.509 & & 2.018 & -0.061 & -3.430 & & 2.183 & -0.084 \\
\hline Education & -0.117 & & 0.727 & -0.008 & -0.056 & & 0.773 & -0.004 \\
\hline \multicolumn{9}{|l|}{ Gender (Female reference) } \\
\hline Male & -9.484 & $* * *$ & 1.649 & -0.278 & -9.420 & $* * *$ & 1.802 & -0.272 \\
\hline \multicolumn{9}{|l|}{$\begin{array}{l}\text { Political ideology (Conservative } \\
\text { reference) }\end{array}$} \\
\hline Moderate & 2.314 & & 1.957 & 0.059 & 2.089 & & 2.178 & 0.053 \\
\hline Liberal & -1.509 & & 2.265 & -0.034 & -0.963 & & 2.829 & -0.019 \\
\hline Haven't thought about it & -3.997 & & 2.456 & -0.084 & -4.685 & & 2.753 & -0.096 \\
\hline Years lived in community & -0.971 & & 0.544 & -0.088 & -1.074 & & 0.587 & -0.098 \\
\hline Civic participation index & 0.003 & & 0.301 & 0.000 & -0.024 & & 0.340 & -0.004 \\
\hline \multicolumn{9}{|l|}{$\begin{array}{l}\text { Generalized trust (You can't be } \\
\text { too careful reference) }\end{array}$} \\
\hline People can be trusted & -6.000 & $* * *$ & 1.619 & -0.184 & -5.805 & $* *$ & 1.735 & -0.176 \\
\hline Depends & -6.613 & $*$ & 3.217 & -0.100 & -5.176 & & 3.555 & -0.075 \\
\hline Ever Victim of Property Crime & -2.136 & & 1.899 & -0.053 & -0.864 & & 2.053 & -0.021 \\
\hline \multicolumn{9}{|l|}{$\begin{array}{l}\text { Feeling of safety at night in } \\
\text { neighborhood (Somewhat or } \\
\text { very unsafe reference) }\end{array}$} \\
\hline Very safe & -11.683 & $* * *$ & 2.316 & -0.369 & -12.102 & $* * *$ & 2.556 & -0.378 \\
\hline Somewhat safe & -4.150 & & 2.278 & -0.130 & -4.838 & & 2.585 & -0.150 \\
\hline Religious attendance & & & & & -0.382 & & 0.646 & -0.036 \\
\hline \multicolumn{9}{|l|}{$\begin{array}{l}\text { Religious denomination (Non- } \\
\text { religious reference) }\end{array}$} \\
\hline Protestant & & & & & 5.951 & & 3.956 & 0.174 \\
\hline Catholic & & & & & 3.959 & & 4.628 & 0.068 \\
\hline Other Christian & & & & & 4.762 & & 4.338 & 0.107 \\
\hline Other Religion & & & & & 7.363 & & 5.956 & 0.083 \\
\hline Constant & 42.422 & $* * *$ & 4.318 & & 39.096 & $* * *$ & 5.776 & \\
\hline R-Squared & 0.259 & & & & 0.254 & & & \\
\hline
\end{tabular}

$*$ Sig at $\mathrm{p}<0.05 ; * *$ Sig at $\mathrm{p}<0.01 ; * * *$ Sig at $\mathrm{p}<0.001$ 


\section{Conclusions}

The current study offers preliminary evidence that religious involvement can reduce fear of crime, though not necessarily in the expected direction. Controlling for all other variables, increased religious attendance was associated with reduced fear of property crime. However, mixed findings emerged regarding religious orientation. Only Catholics and Protestants displayed differences when compared to the non-religious, and for these groups, they displayed higher levels of fear of property crime. This could be due to relatively small sample sizes in the case of Catholics and the non-religious. However, it is also possible that this finding relates to the specific composition of the types of Catholic and Protestant denominations in the study region. Unfortunately, this study did not examine specific religious beliefs or theologies, and thus this statement is speculation. Future research incorporating denominational variations and/or religious beliefs could better uncover explanations behind these seemingly anomalous nuances.

The religion variables were not associated with fear of violent crime. That religious attendance is related to fear of property crime but not violent crime is an interesting finding. Besides any methodological restrictions, one possible reason for this finding has to do with the nature of the sample used in this study. Perhaps property crime is a more salient issue for them, as $42.5 \%$ of respondents in the sample report having been a victim of property crime, while only $18.9 \%$ report having been a violent crime victim. Indeed, the fear of property crime in this sample is relatively high: the mean index score for fear of property crime was nearly as high (22.4) as that for fear of violent crime (24.8), though this is not necessarily unusual in studies of this sort [5]. Also, some specific property crimes had higher fear ratings than some specific violent crimes (for example, the mean for property vandalized of 4.54 versus the mean of 4.11 for robbed or mugged on the street). Another possibility is that the fear-reducing (or trust building) capacity of religion is simply limited, meaning that religious involvement offers enough comfort to reduce fear of property crimes but not the more frightening crimes against the person. As noted, those who report the highest levels of generalized trust are significantly less fearful of both property and violent crime, though individuals who are more muted in their general trust of others showed no significant differences versus those who exhibit the lowest levels of trust. This could extend to the forms of trust generated by religious involvement, which may or may not generally extend to areas of social life such as crime. Ultimately, the processes leading to fear of violent crime and fear of property crime may differ. At any rate, why religious involvement would reduce fear of property but not violent crime needs to be determined by further research that could explore how trust is generated within religious institutions, and how this trust is generalized beyond this arena of social life.

The effect of religious attendance was independent of political ideology, community involvement, and demographic variables. Conservatives did not significantly differ in fear of crime from moderates or liberals, although individuals who seem to be apolitical - those who "haven't thought about" a political ideology — reported less fear of property crime than conservatives. The measure of years lived in the community was significantly and negatively associated with fear of crime across all models. This result could mean simply that residents will reside longer in neighborhoods in which they are less fearful of crime. However, like religious involvement, the length of community tenure potentially indicates the extent to which residents are tied to the community, so it was important to include it as a 
control. Civic participation was insignificant throughout all models. Regarding the demographic variables, consistent with previous research, men reported less fear of crime than women throughout all four models. Race and education were insignificant across all models.

Feeling safe at night in the neighborhood had the strongest impact upon fear of property and violent crime, and its inclusion greatly increased the R-square for each model. Religious attendance remained significant after adding feeling safe, though its impact slightly decreased. Thus, feelings of safety in the neighborhood may also mediate religion's impact upon fear of crime. Perhaps religious persons are more likely to feel safe in their neighborhood which, in turn, reduces their fear of crime, but in this study religious attendance has a clear direct effect controlling for several variables. In total, the results do not suggest that fear of crime among more religious persons can be explained at all by their conservatism or to a great extent by their attachment to the community or gender.

The results of this study differ from the studies reviewed earlier. Lotz found that religion was not associated with fear of crime at all, and the results of the current study run counter to Lotz's hypothesis that religious conservatives worry more about crime [11]. The current study also differs from Sacco and Nakhaie's conclusion that nonelderly religious persons are more likely to fear crime [13], and Mohammed, Saridakis, and Sookram's finding that persons with a religious affiliation were more likely than those without an affiliation to be fearful of crime [15]. Like O'Mahony and Quinn, the current study did not associate religious affiliation with fear of crime [12]. However, their study did not include a measure of religious involvement, which along with other methodological differences, makes it difficult to compare to the current study.

These divergent results from prior studies are quite possibly due to methodological differences. In addition to the use of a small sample that is quite different from those used in the other studies, and that religion was not a focal variable in the other studies, the current study employed different measures of religion and fear of crime. For example, Sacco and Nakhaie and Mohammed, Saridakis, and Sookram used dichotomous measures of religiosity [13,15], and Mohammed, Saridakis, and Sookram used a dichotomous measure of fear of crime [15]. These crude measures simply distinguish between the religious and non-religious and those who are fearful or not fearful of crime, which creates a severe precision problem as there is great variance in the degrees to which people are religious and fearful. Also, Sacco and Nakhaie used behavioral measures of fear of crime, consisting of crime safety behaviors [13], and the current study used the perceptual fear of crime measure developed by Ferraro and LaGrange [5]. Although Sacco and Nakhaie correctly point out that perceptual fear measures are problematic, their approach is also problematic in that they use overt behaviors to indicate an internal emotional state [13]. Crime safety behaviors may be better viewed as behavioral reactions to crime that potentially affect and result from levels of fear of crime, rather than as a proxy for fear of crime.

\subsection{Implications}

As noted in previous sections of the manuscript, this study suffers from certain limitations. The sample size of 380 is acceptably large for many types of analysis, but it can create issues when attempting to examine variations across many categories, such as religious denominations. This limited the analyses of religious differences to those of major affiliations, which obscures important denominational differences, as noted in the previous section. For example, those Protestants that 
adhere to a more conservative theology may have quite different belief systems regarding fear of crime than rather liberal Protestants [34]. Relatedly, more in depth measures of religious beliefs could help more effectively elucidate differences in fear of crime, in a similar manner to recent research which has demonstrated differences in gender beliefs rooted in religious ideology [35].

However, the results reported here indicate that more frequent religious involvement, as measured by worship attendance, is inversely related to fear of property crime. This lends credence to the idea that religious activity provides individuals with access to social networks that provide fear-reducing resources and even facilitate higher levels of generalized trust. If this link is genuine, it represents another positive outcome of religious activity. As discussed earlier, such generalized trust is a crucial element of life in a complex, modern world [20,21]. Even though fear of crime may be beneficial to the extent that it motivates a person to take precautions against victimization, thereby increasing feelings of safety, fear is an undesirable emotion that potentially reduces one's well-being and quality of life [31].

In addition to further expanding our understanding of correlates with fear of crime, future research should examine other important victimization variables as well. It remains to be seen how religious involvement impacts other subjective appraisals of crime threats (e.g., perceived risk and general concern) as well as actual victimization. Also, more research is needed to specify what it is about religion that reduces fear of crime. The trust generated by participation in religious activities is one possibility, but other dimensions of religious life could also be involved in determining levels of fear. More personal religious activities such as prayer, meditation, and reading sacred texts, for example, may serve as routine activities that alleviate one's fears. Individualized religious coping activities such as prayer have also been found to reduce distress [36,37]. However, the current study does suggest that religious involvement is not spuriously related to fear of crime via community attachment or conservative identity. Future researchers should seek to explore the nuances of the general relationship between religion, trust, and fear of crime.

\section{Acknowledgements}

The authors would like to thank the reviewers and the Special Issue editor for helpful comments.

\section{References and Notes}

1. Akers, R.L. Religion and crime. Criminologist 2010, 35, 1-6.

2. Baier, C.J.; Wright, B.R.E. "If you love me, keep my commandments": A meta-analysis of the effect of religion on crime. J. Res. Crime Delinq. 2001, 38, 3-21.

3. Ferraro, K.F. Fear of Crime: Interpreting Victimization Risk; State University of New York Press: Albany, NY, USA, 1995; p. 4.

4. Gabriel, U.; Greve, W. The psychology of fear of crime: Conceptual and methodological perspectives. Br. J. Criminol. 2003, 43, 600-614.

5. Ferraro, K.F. Fear of Crime: Interpreting Victimization Risk; State University of New York Press: Albany, NY, USA, 1995.

6. Gray, E.; Jackson, J.; Farrall, S. Reassessing the fear of crime. Eur. J. Criminol. 2008, 5, 363-380. 
7. Zhao, J.S.; Lawton, B.; Longmire, D. An examination of the micro-level crime-fear of crime link. Crime Delinq. 2010, 20, 1-26.

8. Weinrath, M.; Clarke, K.; Forde, D.R. Trends in fear of crime in a western Canadian City: 1984, 1994, and 2004. Can. J. Criminol. Crim. Justice 2007, 49, 617-646.

9. McCrea, R.; Shyy, T.; Western, J.; Stimson, R.J. Fear of crime in Brisbane: Individual, social, and neighbourhood factors in perspective. J. Sociol. 2005, 41, 7-27.

10. Newman, G.R.; Trilling, C. Public perceptions of criminal behavior: A review of the literature. Crim. Justice Behav. 1975, 2, 217-236.

11. Ammerman, N.T. Congregation and Community; Rutgers University Press: New Brunswick, NJ, USA, 1996.

12. Ammerman, N.T. 1996 Presidential Address: Organized Religion in a Voluntaristic Society. Soc. Relig. 1997, 58, 203-215.

13. Ammerman, N.T. Pillars of Faith: American Congregations and Their Partners; University of California Press: Berkeley, CA, USA, 2005.

14. Beyerlein, K.; Hipp, J. From Pews to Participation: The Effect of Congregation Activity and Context on Bridging Civic Engagement. Soc. Probl. 2006, 53, 97-117.

15. Park, J.Z.; Smith, C. 'To Whom Much Has Been Given...': Religious Capital and Community Voluntarism among Churchgoing Protestants. J. Sci. Study Relig. 2000, 39, 272-286.

16. Uslaner, E.B. The Moral Foundations of Trust; Cambridge University Press: Cambridge, UK, 2002.

17. Uslaner, E.B. Religion and Civic Engagement in Canada and the United States. J. Sci. Study Relig. 2002, 41, 239-254.

18. Welch, M.; Sikkink, D.; Loveland, M.T. The Radius of Trust: Religion, Social Embeddedness and Trust in Strangers. Soc. Forces 2007, 86, 23-46.

19. Uslaner, E.B. Producing and Consuming Trust. Polit. Sci. Q. 2000, 115, 569-590.

20. Luhmann, N. Familiarity, Confidence, Trust: Problems and Alternatives. In Trust; Gambetta, D., Ed.; Basil Blackwell: Oxford, UK, 1988; pp. 94-107.

21. Yamagishi, T.; Yamagishi, M. Trust and Commitment in the United States and Japan. Motiv. Emot. 1994, 18, 129-166.

22. Lotz, R. Public anxiety about crime. Pac. Social. Rev. 1979, 22, 241-254.

23. O'Mahony, D.; Quinn, K. Fear of crime and locale: The impact of community related factors upon fear of crime. Int. Rev. Vict. 1999, 6, 231-251.

24. Sacco, V.F.; Nakhaie, M.R. Coping with crime: An examination of elderly and nonelderly adaptations. Int. J. Law Psychiatr. 2001, 24, 305-323.

25. Mohammed, A.; Saridakis, G.; Sookram, S. Do victims of crime fear more crime? Empirical evidence from the Survey of Living Conditions (2005) of Trinidad and Tobago. In SALISES Publications: Working Papers 19; University of West Indies: Trinidad and Tobago, 2009.

26. Ferraro, K.F. Women's fear of crime: Shadow of sexual assault? Soc. Forces 1996, 75, 667-690.

27. Fisher, B.S.; Sloan, J.J. Unraveling the fear of victimization among college women: Is the "shadow of sexual assault hypothesis" supported? Just. Q. 2003, 20, 633-660.

28. Reid, L.W.; Konrad, M. The gender gap in fear: Assessing the interactive effects of gender and perceived risk on fear of crime. Soc. Spectrum 2004, 24, 399-425. 
29. Schafer, J.A.; Huebner, B.M.; Bynum, T.S. Fear of crime and criminal victimization: Genderbased contrasts. J. Crim. Just. 2006, 34, 285-301.

30. Sutton, R.M.; Farrall, S. Gender, socially desirable responding, and the fear of crime. $B r . J$. Criminol. 2005, 45, 212-224.

31. Jackson, J.; Gray, E. Functional fear and public insecurities about crime. Br. J. Criminol. 2010, 50, 1-22.

32. Walkate, S. Crime and community: Fear or trust? Br. J. Sociol. 1998, 49, 550-569.

33. Robinson, J.B.; Lawton, B.A.; Taylor, R.B.; Perkins, D.D. Multilevel longitudinal impacts of incivilities: Fear of crime, expected safety, and block satisfaction. J. Quant. Criminol. 2003, 19, 237-274.

34. Hempel, L.M.; Bartkowski, J.B. Scripture, Sin and Salvation: Theological Conservatism Reconsidered. Soc. Forces 2008, 86, 1647-1674.

35. Bartkowski, J.B.; Hempel, L.M. Sex and gender traditionalism among conservative Protestants: Does the difference make a difference? J. Sci. Stud. Relig. 2009, 41, 805-816.

36. Nooney, J.; Woodrum, E. Religious coping and church-based social support as predictors of mental health outcomes: Testing a conceptual model. J. Sci. Stud. Relig. 2002, 41, 359-368.

37. van Olphen, J.; Shulz, A.; Israel, B.; Chatters, L.; Klem, L.; Parker, E.; Williams, D. Religious involvement, social support, and health among African-American women on the east side of Detroit. J. Gen. Intern. Med. 2003, 549-557.

\section{Appendix A: Survey Questions}

At one time or another, most of us have experienced fear about becoming the victim of crime. Some crimes probably frighten you more than others. We are interested in how afraid people are in everyday life of being a victim of different kinds of crimes. Please rate your fear on a scale of 1 to 10 where 1 means you are not afraid at all and ten means you are very afraid. How fearful are you of...

being approached on the street by a beggar or panhandler

being cheated, conned, or swindled out of your money

having someone break into your home while you are away

having someone break into your home while you are there

being raped or sexually assaulted

being murdered

being attacked by someone with a weapon

having your car stolen

being robbed or mugged on the street

having your property damaged by vandals

How safe do you feel out alone in your neighborhood at night. Do you feel.

Very safe

Somewhat safe

Somewhat unsafe

Very unsafe

DON'T KNOW 
Have you ever been the victim of a property crime?

YES

NO

DON'T KNOW

REFUSED

Have you ever been the victim of a violent crime?

YES

NO

DON'T KNOW

REFUSED

Which of the following best describes the highest level of education you have completed?

Less than high school

Some high school

Graduated high school/GED

Some college/Associate degree/vocational or trade school

College graduate

Graduate or Professional Degree (Master's, Ph.D., M.D., J.D., etc.)

REFUSED

Please stop me when I reach the category that best describes you...

White or Caucasian

Black or African American

American Indian or Alaska Native

Asian

Native Hawaiian or Other Pacific Islander

Two or more (SPECIFY)

Other (SPECIFY)

DON'T KNOW

REFUSED

Are you male or female?

Male

Female

Other

REFUSED

Which of the following best describes your political views?

Extremely conservative

Conservative

Slightly conservative

Moderate

Slightly liberal

Liberal 
Extremely liberal

Haven't thought about it

DON'T KNOW

REFUSED

How many years have you lived in your community?

LESS THAN ONE YEAR

ONE TO FIVE YEARS

SIX TO TEN YEARS

ELEVEN TO TWENTY YEARS

MORE THAN TWENTY YEARS

ALL YOUR LIFE

DK

REFUSED

Generally speaking, would you say that most people can be trusted or that you cannot be too careful in dealing with people?

People can be trusted

You cannot be too careful

DEPENDS

DK

REFUSED

Now I'd like to ask you about other types of groups and organizations. I'm going to read a list. Just answer 'yes' if you have been involved with this kind of local group in the past 12 months (other options are "no," “don't know," or "refused”).

Any organization affiliated with religion

An adult sports club, league or outdoor activity club

A youth organization like the Scouts, $4 \mathrm{H}$ clubs,

Boys and Girls Clubs or youth sports leagues

A PTA, PTVO, or other school support or service groups

A veteran's group

A neighborhood, homeowner, or tenant association

How about a neighborhood crime watch group

A senior citizens or older persons group

A charitable organization that provides services to the needy

A labor union, professional, trade, farm, or business association

An environmental group

Service clubs such as the Lions, Kiwanis, Rotary, a women's club or other service group

A support group or self-help program for people with specific illnesses, disabilities, problems, or addictions, or for their families

Ethnic, nationality, or civil rights organizations

Other public interest or political groups or party committees

A literary or art discussion group or a musical, dancing, or singing group

Any other hobby, investment, or garden clubs or societies 
Not including weddings and funerals, how often do you attend religious services?

Every week

Almost every week

Once or twice a month

A few times a year

Less often than that

DON'T KNOW

REFUSED

What is your religious preference? Is it Protestant, Catholic, another type of Christian, Jewish, some other religion, or no religion?

Protestant

Catholic

Other Christian

Jewish

Some other religion

No religion

DON'T KNOW

REFUSED

(C) 2011 by the authors; licensee MDPI, Basel, Switzerland. This article is an open access article distributed under the terms and conditions of the Creative Commons Attribution license (http://creativecommons.org/licenses/by/3.0/). 